\title{
GENERALIZED HYERS-ULAM-RASSIAS STABILITY OF FUNCTIONAL INEQUALITIES AND FUNCTIONAL EQUATIONS
}

\section{Zhen-Xia Gao, Huai-Xin CaO, Wen-Ting Zheng and Lu Xu}

Abstract. In this paper, the definitions of the stability of functional inequalities and functional equations are given. Also we prove the generalized Hyers-Ulam-Rassias stability of the following functional inequality and functional equation

$$
\begin{aligned}
\|f(x)+f(y)+2 f(z)\| & \leqslant\left\|2 f\left(\frac{x+y}{2}+z\right)\right\|, \\
f(x)+f(y)+2 f(z) & =2 f\left(\frac{x+y}{2}+z\right),
\end{aligned}
$$

in the spirit of the Hyers' direct method for approximately additive mappings.

Mathematics subject classification (2000): 39B82.

Keywords and phrases: Functional inequality, functional equation, additivity, stability, generalized Hyers-Ulam-Rassias stability.

\section{REFERENCES}

[1] S. M. Ulam, A Collection of the Mathematical Problems, Interscience Publ., New York, 1960.

[2] D. H. HYERS, On the stability of the linear functional equation, Proc. Natl. Acad. Sci. USA 27 (1941) 222-224.

[3] TH. M. Rassias, On the stability of the linear mapping in Banach spaces, Proc. Amer. Math. Soc. 72 (1978) 297-300.

[4] Th. M. Rassias, Problem 16; 2, in: Report of the 27th International Symp. on Functional Equations, Aequationes Math. 39 (1990) 292-293.

[5] Z. GAJDA, On stability of additive mappings, Int. J. Math. Math. Sci. 14 (1991) 431-434.

[6] TH. M. RASSIAS, P. ŠEMRL, On the behaviour of mappings which do not satisfy Hyers-Ulam stability, Proc. Amer. Math. Soc. 114 (1992) 989-993.

[7] P. GǍVRUTA, A generalization of the Hyers-Ulam-Rassias stability of approximately additive mappings, J. Math. Anal. Appl. 184 (1994) (2000) 431-436.

[8] S. JUnG, On the Hyers-Ulam-Rassias stability of approximately additive mappings, J. Math. Anal. Appl. 204 (1996) 221-226.

[9] P. Czerwik, Functional Equations and Inequalities in Several Variables, World Scientific, New Jersey, Hong Kong, Singapore and London, 2002.

[10] D. H. Hyers, G. Is AC, Th. M. Rassias, Stability of Functional Equation in Several Variables, Rirkhäuser, Basel, 1998.

[11] J. M. RASSIAS, On approximation of approximately linear mappings by linear mappings, Bull. Sci. Math. 108 (1984) 445-446.

[12] G. Is AC, TH. M. RAssias, Stability of additive mappings: Applications to nonlinear analysis, Int. J. Math. Math. Sci. 19 (1996) 219-228.

[13] D. H. Hyers, G. Is AC, TH. M. Rassias, On the asymptoticity aspect of Hyers-Ulam stability of mappings, Proc. Amer. Math. Soc. 126 (1998) 425-420.

[14] C. PARK, On the stability of the linear mapping in Banach modules, J. Math. Anal. Appl. 275 (2002) $711-720$ 
[15] C. PARK, Isomorphisms between unital $C^{*}$-algebras, J. Math. Anal. Appl. 307 (2005) 753-762.

[16] C. PARK, Hyers-Ulam-Rassias stability of homomorphisms in quasi-Banach algebras, Bull. Sci. Math. 132 (2008) 87-96.

[17] TH. M. RASSiAs, The problem of S. M. Ulam for approximately multiplicative mappings, J. Math. Anal. Appl. 246 (2000) 352-378.

[18] TH. M. RAssias, On the stability of functional equations in Banach spaces, J. Math. Anal. Appl. 251 (2000) 264-284.

[19] TH. M. Rassias, Functional Equations, Inequalities and Applications, Kluwer Academic, Dordrecht, Boston and London, 2003.

[20] F. Skof, Proprietà localie approssimazione di operatori, Rend. Sem. Mat. Fis. Milano 53 (1983) $113-129$.

[21] J. M. RASSIAS, On approximation of approximately linear mappings by linear mappings, J. Funct. Anal. 46 (1982) 126-130.

[22] J. M. Rassias, Solution of a problem of Ulam, J. Approx. Theory 57 (1989) 268-273.

[23] J. M. RASsias, Complete solution of the multi-dimensional problem of Ulam, Discuss. Math. 14 (1994) 101-107.

[24] J. M. RASSIAS, M. J. RASSIAS, On some approximately quadratic mappings being exactly quadratic, J. Indian Math. Soc. 69 (2002) 155-160.

[25] C. BAAK, D. Boo, TH. M. RASSIAS, Generalized additive mapping in Banach modules and isomorphisms between $C^{*}$-algebras, J. Math. Anal. Appl. 314 (2006) 150-161.

[26] C. T. NG, Jensens functional equation on groups, Aequationes Math. 39 (1990), 85-90.

[27] J. C. Parnami, H. L. Vasudeva, On Jensens functional equation, Aequationes Math. 43 (1992), 211-218.

[28] H. Haruki, Th. M. Rassias, New generalizations of Jensens functional equation, Proc. Amer. Math. Soc. 123 (1995), 495-503. 